absorbed, is probably one of very great rapidity, the movement of such substances is always controlled by the laws of diffusion. Mangham, however, speaks of an "adsorptive suction."

With regard to Mangham's " wave" concept, I must confess to having experienced some difficulty in arriving at a point of view from which this mental picture is comprehensible. It appears to have had its origin in the application of a false analogy. Mangham states that "a wave of disturbance and readjustment of equilibrium is propagated, in much the same way as the firing of shells from a battery leads to the depletion of the immediate supply, followed by a replenishing from the reserves, etc., and ultimately from the factory, so that the scheduled relations are maintained between the various stores at intermediate points." It is clear that in this picture, which involves the intervention of human activity in the replenishing of reserve dumps successively from the rear, the conception of a wave is not altogether inapplicable. Nevertheless, if the shells represent sugar molecules and the dumping spots absorbing particles, its use as an analogy is entirely false and misleading. It obviously involves a diffusion of sugar against the diffusion gradient.

\title{
PRANKLIN KIDD.
}

St. John's College, Cambridge.

\section{THE OSAZONE METHOD FOR DETECTING SUGARS}

\section{IN PLANT TISSUES.}

TN a recent number of this journal, S. Mangham offers some 1 explanations of his earlier writings on the osazone method for detecting sugars in plant tissues. In the course of his note he calls attention to a passing reference made by us in regard to the detection of sugars in which we said "The fact that Mangham should claim to distinguish between $d$-glucose and $d$-fructose in the plant by the osazone test, when their phenyl osazones are of course identical, is not very reassuring as to the degree of reliability of his results."

Mangham is in error in reading into this statement an assumption that he considers a chemical difference to exist between the phenyl osazones yielded by glucose and fructose. These sugars yield the same phenyl osazone. Many chemists feel sceptical of microchemical tests applied to plant tissue and would only fall 
back on them when others are not available. Further, the osazone tests are of doubtful applicability in the case of mixtures of sugars. Such mixtures are present in plant cells. For these reasons we felt and still feel that a claim (even if it is only a half claim) to distinguish between two sugars in plant tissue by means of the osazone test, when the two sugars yield the same osazone, is not very reassuring as to the degree of reliability of the results obtained, even if there is "a question of the influence of viscosity upon molecular rearrangements, diffusion and crystal formation," which results in the formation of different crystal aggregates.

Nevertheless, readers might be excused for drawing from the section of Mangham's paper headed "Effects of Glycerine" the conclusion that Mangham considered glucose and fructose to yield different osazones, for he speaks of "dextrose and levulose phenyl osazones," "the two osazones," "the osazones." Above all the description of Bxperiment III, in which "levulose and dextrose phenyl osazones were added to pure glycerine" and the behaviour of the resulting mixtures of osazone and glycerine compared, seems to assume the existence of two osazones, and the experiment appears to have for its object a determination of different properties of the two. In our opinion the use of the expression " two osazones" in Mangham's paper for different forms of crystal aggregate of the same osazone is liable to misinterpre. tation, just as Mangham's use of the symbols ' $d$ ', ' $l$ ' and ' $d l$ ' to represent the types of osazone crystal aggregates yielded by glucose, fructose and sucrose respectively, does not conduce to clearness of thought when the symbols $d, l$ and $d l$ have a univerally accepted and quite different signification in sugar chemistry.

However, as Mangham has now made his position clear, further discussion is unnecessary. With his conclusion that Senft's reagent cannot be used to distinguish with certainty the individual sugars of a mixture we certainly agree. With regard to his further conclusion that this reagent is of considerable value in certain forms of research we feel some scepticism; it is a nice question whether it is ever worth while employing a bad method that can at best only give questionable results "indicating probabilities rather than as affording demonstrations." It appears to us that in many cases the result would be the expenditure of time in accumulating data of little value, accompanied by what is perhaps worse, a tendency to accept "probabilities" as facts. 
This document is a scanned copy of a printed document. No warranty is given about the accuracy of the copy. Users should refer to the original published version of the material. 